\title{
Nursing Assessment for Predictors of Failed Weaning Among Prolonged Mechanically Ventilated Patients
}

\author{
Mahmoud Ahmed Mohamed ${ }^{1}$, Mona Aly Mohamed ${ }^{2}$ \& Mona Abd Elaziem Ahmed ${ }^{3 .}$ \\ 1. Clinical instructor at Assuit technical institute of health, Egypt. \\ 2. Assistant professor of critical care nursing, faculty of nursing Assuit university, Egypt. \\ 3. Lecturer of critical care nursing, faculty of nursing Assuit university, Egypt.
}

\begin{abstract}
Background: For adult patients with prolonged mechanical ventilation ( $\mathrm{PMV} \geq 7$ days), weaning success is an important prognostic factor in patients requiring prolonged mechanical ventilation. Weaning failure has been attributed to various factors. The aim: of the study was to identify factors contributing to long term mechanical ventilation. A Descriptive research design was adopted to conduct this study. The study was conducted in the intensive and trauma care units at Assuit university. A convenient sample: of sixty adult male and female patients admitted to mentioned settings and connected to MV. Tools: Tool one: socio-gemograghic data and clinical data, Tool two: weaning criteria scale, Tool three APACHE II score Tool four: Neurological assessment by using FOUR score. Results: the most common risk factors delay weaning were cardiovascular $(66 \%)$ and neuromuscular (54.2\%). Conclusion: a highly statistically significant relation was found regarding to factors as age, length of ICU stays, RSBI, PH, hemoglobin, WBCs, platelets count and respiratory rate. Recommendations: 1-good monitoring of the cardiovascular assessment with cardiologists 2- the weaning indexes have some limitations, related to study population 3- integration with other departments should be morely supported.
\end{abstract}

\section{Key words: Failed Weaning, Weaning Failure, Prolonged Mechanical Ventilation \& Predictors.}

\section{Introduction}

Mechanical ventilation is a lifesaving intervention, but it is not without complications. Most patients require short periods of respiratory support, but minority require prolonged MV. Shortening the ventilator time has shown to reduce ventilator-related complications (Andres \& Jorge, 2018).

Weaning is an essential and universal element in the care of critically ill intubated patients. Weaning covers the entire process of gradual withdrawal and liberating the patient from mechanical support and from the endotracheal tube, and it comprises at least $40 \%$ of the total duration of MV (Hossam, et al., 2016).

The ultimate goal of caring for patients using mechanical ventilator is to obtain spontaneous breathing and successful weaning off the ventilator. Weaning process requires a multidisciplinary care team, including the anesthesiologist, respiratory therapist, physical therapist, nutritionists and nurses have the coordinating role in this team (Ali, et al., 2015).

The decision to attempt discontinuation of mechanical ventilation has largely been based on the clinician's assessment (Hala \& Wegdan, 2016). Commonly, factors affecting the decision making include the verification of hemodynamic stability, resolution of primary cause for which the patient was intubated, cardiovascular stability, no continuous sedation and adequate oxygenation defined as $\mathrm{paO} / \mathrm{FiO} 2$ of at least $150 \mathrm{mmHg}$ with positive end-expiratory pressure (PEEP) up to $8 \mathrm{cmH} 2 \mathrm{O}$, nutritional status, mental and cognitive status (Mariana, et al., 2018) these criteria should be thought of as considerations rather than as rigid thresholds that patients must meet all of them to be successfully weaned. Because many patients were successfully discontinued from the ventilator although they didn't meet one or more of them (Hossam, et al., 2016).

A new classification of patients into three groups is proposed, as suggested by Brochard during the International Consensus Conference, according to the difficulty and length of the weaning process Simple weaning Patients who proceed from initiation of weaning to successful extubation on the first attempt without difficulty, Difficult weaning Patients who fail initial weaning and require up to three spontaneous breathing trial (SBT) or as long as 7 days from the first SBT to achieve successful weaning and Prolonged weaning: Patients who fail at least three weaning attempts or require more than 7 days of weaning after the first SBT (Adel, et al., 2017).

Prolonged mechanical ventilation is variously defined as need for positive pressure ventilation for more than 3 days as (patricia \& Dorrie, 2018) or 7 days as (Béduneau, et al., 2017) or for more than 14 days as (Guillermo, et al., 2016) (Hough, et al., 2015) or for more than 21 days as regard for (Loss, et al., 2015). weaning success is an important prognostic factor in patients requiring prolonged mechanical ventilation. Failure to wean from mechanical ventilator is a 
significant clinical and economic problem. Prolonged mechanical ventilator is associated with numerous complications including increase morbidity and mortality, increase respiratory tract problems, hemodynamic instability, cardiovascular disorder, sedatives dependency, skin fragility, gastrointestinal stress and reduced functional status and quality of life (Mifsud, et al., 2016).

provision of nursing care to the patient receiving MV requires further attention, because, if not provided properly, it can lead to complications and aggravation of the patient's clinical condition. Monitoring patients receiving ventilatory support is a factor of primary importance. Patients receiving MV require accurate nursing care, such as tracheal suction; control of the balloon (cuff) pressure of the ETT, change of decubitus; safe transportation to other hospital units; actions to prevent complications such as aspiration pneumonia or ventilator-associated pneumonia, pressure ulcers, unplanned extubation, barotrauma, and pneumothorax (Elizabeth, et al., 2014) Identifying strategies to reduce the duration on MV and to restore ventilatory autonomy is an immediate priority from the moment of its commencing (Rojek, et al., 2015) Most international researcher have attempted to find better indexes or parameters (predictors) which can predict the weaning outcome in the best possible way (Ali, et al., 2015) to date, results are still controversial and the best strategy has not yet been established due to the multifactorial origin of liberation from mechanical ventilation (Elkins \& Dentice, 2015) several weaning predictors have been used in clinical practice trying to objective assist the decision making of the weaning process (Quellette, et al., 2017).

Over the past several years, many risk factors affect the weaning process. Factors that should be considered in all patients include misadjusted ventilator settings, infections, airway patency and respiratory muscle performance. Malnutrition, heart failure or coronary ischemia. A number of electrolyte imbalances and psychological problem (Adel, et al., 2017).

\section{Significance of the study}

Prolonged mechanical ventilator is associated with numerous complications including increase morbidity and mortality, increase respiratory tract problems, hemodynamic instability, cardiovascular disorder, sedatives dependency, skin fragility, gastrointestinal stress and reduced functional status and quality of life. (Herwanto, et al., 2018).

In 2016, the number of patients connected with mechanical ventilation at trauma intensive care unit was about (410) patients and about (320) patients at general intensive care unit. (Assuit university hospital records, 2017).

Hence, the purpose of this study is to identify risk factors associated with weaning failure in mechanically ventilated patients.

(Herwanto, et al., 2018).

\section{Aim of the study}

To identify the Predictors of weaning failure among prolonged mechanically ventilated patients among critically ill patient.

\section{Research question}

What are the risk factors of weaning failure among prolonged mechanically ventilated patients among critically ill patients at Assuit university hospital?

Operational definition

Prolonged mechanically ventilated patients are Patients who fail at least three weaning attempts or require more than 7 days of weaning after the first SBT.

\section{Research Design}

Descriptive research design was utilized to conduct the aim of this study.

\section{Setting}

The study was conducted in the General intensive care unit and trauma intensive care unit at Assuit university hospital.

\section{Study Subjects}

60 adult male and female patients underwent the study were admitted to the above-mentioned settings will be included in the study and failed at least 1 st spontaneous breathing trial (SBT) or require mechanical ventilation for more than 7 days will be included in the study.

\section{Exclusion criteria}

- patient who mechanically ventilated due to malignant lung tumors, neurological disorders as myasthenia gravis, Guillain barre syndrome, brain tumors and brain stem death and patients who discharged before seven days after the first attempt of weaning were excluded from this study.

\section{Tools}

Four tools were used to collect the data in this study and developed by the researcher based on reviewing of related literature

Tool I: "patient assessment sheet"

This tool is developed by the researcher to assess the patient's demographic data and health relevant data during period of intubation and it comprised 4 parts:

Part 1: sociodemographic and clinical data which include (age, sex, weight of patient, body mass index (BMI), date of admission, medical diagnosis, length of stay and duration on mechanical ventilation)

Part 2: Hemodynamic monitoring which include (vital signs, CVP, pulsy oximeter). 
Part 3: mechanical ventilator parameters which include (mode of ventilation, tidal volume, respiratory rate, fraction of inspired oxygen, pressure support, positive end expiratory pressure and Rapid shallow breathing index)

Part 4: lab investigations which include (CBC, serum electrolytes, hepatorenal function, $\mathrm{ABG}$ interpretation).

\section{Tool II: weaning criteria scale}

According to the international consensus conference recommendations in 2005, some of derivate criteria of readiness for weaning trial are tabled and these criteria should be thought of as considerations rather than as rigid thresholds that patients must meet all of them to be successfully weaned. Because many patients were successfully discontinued from the ventilator although they didn't meet one or more of them (Hossam, et al., 2016).

Tool III: Acute Physiology \& Clinical Health Evaluation II (APACHE II)

APACHE II score is a severity-of-disease classification system it is one of several ICU scoring systems which applied within 24 hours of admission of a patient to an intensive care unit (ICU): The first APACHE score was presented by Knaus et al in 1981(Knaus, et al., 1985).

The APACHE II score is made of 12 physiological variables all ICU patients had all 12 physiologic measurements available. The worst physiological variables were collected within the first 24 hours of ICU admission. The "worst" measurement was defined as the measure that correlated to the highest number of points. The study did not continually calculate an APACHE II scores beyond the first 24 hours of ICU admission. The APACHE II score ranges from 0 to 71 points; higher scores correspond to more severe disease and a higher risk of death. however, it is rare for any patient to accumulate more than 55 points (Michael \& Lucila, 2014).

\section{Apache II Score / Approximate Mortality}

\begin{tabular}{||c|c||}
\hline \hline 0 to 4 points: & $4 \%$ non-op, $1 \%$ post-op \\
\hline 5 to 9 points: & $8 \%$ non-op, $3 \%$ post-op \\
\hline 10 to 14 points: & $15 \%$ non-op, $7 \%$ post-op \\
\hline 15 to 19 points: & $24 \%$ non-op, $12 \%$ post-op \\
\hline 20 to 24 points: & $40 \%$ non-op, $30 \%$ post-op \\
\hline 25 to 29 points: & $55 \%$ non-op, $35 \%$ post-op \\
\hline 30 to 34 points: & Approx. $73 \%$ both \\
\hline 35 to 100 points: & $85 \%$ non-op, $88 \%$ post-op \\
\hline \hline
\end{tabular}

(Mohammad, et al., 2017)
Scoring of age regarding to the APACHE scoring

\begin{tabular}{|c|c|}
\hline Age in years & APACHE score \\
\hline$\leq 44$ & 0 \\
\hline $45-54$ & 2 \\
\hline $55-64$ & 3 \\
\hline $65-74$ & 5 \\
\hline$\geq 75$ & 6 \\
\hline
\end{tabular}

(Mohammad, et al., 2017)

Tool IV: Neurological assessment by using Full Outline of Unresponsiveness (FOUR) score

The FOUR Score is a clinical grading scale designed for use by medical professionals in the assessment of patients with impaired level of consciousness. It was developed by Eelco F.M at 2005. The FOUR Score is a 17-point scale (with potential scores ranging from 0 - 16). Decreasing FOUR Score is associated with worsening level of consciousness. The FOUR Score assesses four domains of neurological function: eye responses, motor responses, brainstem reflexes, and breathing pattern.

By contrast to the Glasco coma scale (GCS), the FOUR score doesn't rely on a verbal response. In the ICU, a variety of conditions such as intubation, sedation, or delirium preclude reliable assessment of a verbal response and, therefore, the FOUR score is an attractive tool (Wijdicks, et al, 2005).

\begin{tabular}{|c|c|}
\hline Score & Item \\
\hline $0-7$ & Sever \\
\hline $8-14$ & Moderate \\
\hline $15-16$ & Mild \\
\hline
\end{tabular}

\section{Operational design}

It includes preparatory phase, field work phase "implementation phase" and evaluation phase.

\section{preparatory phase}

after reviewing the recent related literatures, study tools were developed.

\section{Content validity}

Content validity of the developed tools was carried out by a jury of 7 specialists in the field of critical care nursing and critical care medicine, the necessary modifications were done in the first tool and we ought to change the fourth tool which was Glasgow coma scale by the full outline of un responsiveness. The overall reliability of the tools was tested using $(\alpha)$ Cronbach's test for the pilot study results.

Pilot study

A pilot study was carried out before starting of data collection to test the feasibility, applicability and the clarity of the study tools on $10 \%$ (6 patients) of the sample and the necessary modifications were done. The pilot study patients were included in the study sample.

The overall reliability of the tools was tested using ( $\alpha$ ) Cronbach's test (.90) for the pilot study results. 
Field work "implementation phase"

An official permission from the dean of faculty of nursing to conduct this study was delivered to the hospital authorities at Assuit university hospital and approval to conduct this study was obtained after explanation of the aims of study.

Sampling was started from the first of October 2017 until the end of August 2018.

\section{Ethical considerations}

An approval was obtained from the local ethical committee and the study followed the common ethical principles in clinical research, written consent was obtained from patient or from the responsible person for the unconscious patients after explanation of the nature and the purpose of the study, patients and their families were assured that the data of this research will not be used without second permission, confidentiality of subjects data and anonymity of patients were assured, there is no risk for study subjects during application of the study and the patient had the right to refuse to participate or withdraw from the study without any rational at any time.

\section{Statistical analysis}

The collected data were coded then transformed into coding sheets. The results were checked. Then, the data were entered into statistical packing for social science (SPSS) version (16) using personal computer. Output drafts were checked against the revised coded data for typing and spelling mistakes. Finally, analysis and interpretation of data were conducted. Descriptive statistics including frequency, distribution, mean and standard deviation were used to describe different characteristics. P-value is considered significant when $\mathrm{p}<0.05$.

\section{Results}

Table (1): Distribution of the Sociodemographic and clinical data of patients on mechanical ventilator $(n=60)$.

\begin{tabular}{|c|c|c|c|c|}
\hline \multirow{2}{*}{\multicolumn{2}{|c|}{ Item }} & Success $(n=36)$ & Failed $(n=24)$ & \multirow{2}{*}{ P-value } \\
\hline & & Mean \pm SD & Mean \pm SD & \\
\hline \multicolumn{2}{|l|}{ Age (years) } & $40.75 \pm 15.86$ & $49.54 \pm 16.69$ & $0.040 *$ \\
\hline \multirow[b]{2}{*}{ Sex: No. (\%) } & male & $29(80.6 \%)$ & $15(62.5 \%)$ & \multirow{2}{*}{0.121} \\
\hline & female & $7(19.4 \%)$ & $9(37.5 \%)$ & \\
\hline \multicolumn{2}{|l|}{ Weight } & $76.47 \pm 12.36$ & $77.08 \pm 15.11$ & 0.964 \\
\hline \multicolumn{2}{|l|}{ Height } & $170.89 \pm 8.38$ & $167.71 \pm 8.26$ & 0.059 \\
\hline \multicolumn{2}{|c|}{ Body Mass Index } & $26.04 \pm 2.51$ & $27.26 \pm 4.16$ & 0.473 \\
\hline \multirow{5}{*}{$\begin{array}{l}\text { Primary } \\
\text { diagnosis: }\end{array}$} & spiratory & $7(19.4 \%)$ & $6(25.0 \%)$ & 0.609 \\
\hline & & $4(11.1 \%)$ & $8(33.3 \%)$ & $0.050 *$ \\
\hline & urological & $17(47.2 \%)$ & $4(16.7 \%)$ & $0.015 *$ \\
\hline & gical & $5(13.9 \%)$ & $4(16.7 \%)$ & 1.000 \\
\hline & patorenal & $3(8.3 \%)$ & $2(8.3 \%)$ & 1.000 \\
\hline
\end{tabular}

Table (2): comparison between the succeed and failed groups in relation to parameters of mechanical ventilator $(\mathrm{n}=60)$

\begin{tabular}{|c|c|c|c|c|}
\hline \multirow{2}{*}{\multicolumn{2}{|c|}{ Item }} & \multirow{2}{*}{$\begin{array}{c}\text { Success }(n=36) \\
\text { Mean } \pm \text { SD }\end{array}$} & \multirow{2}{*}{$\begin{array}{c}\text { Failed }(\mathbf{n}=\mathbf{2 4}) \\
\text { Mean } \pm \text { SD }\end{array}$} & \multirow{2}{*}{ P-value } \\
\hline & & & & \\
\hline \multirow{3}{*}{$\begin{array}{l}\text { Tidal volume } \\
\text { (Vt) }\end{array}$} & $1^{\text {st }}$ day on MV & $471.56 \pm 58.38$ & $448.75 \pm 59.06$ & 0.124 \\
\hline & $7^{\text {th }}$ day on MV & $451.33 \pm 60.16$ & $479.17 \pm 42.32$ & 0.058 \\
\hline & Last day on MV & $442.78 \pm 40.43$ & $471.87 \pm 37.96$ & $0.002 *$ \\
\hline \multirow{3}{*}{$\begin{array}{l}\text { Respiratory rate } \\
\text { (F) }\end{array}$} & $1^{\text {st }}$ day on MV & $13.61 \pm 1.95$ & $14.46 \pm 3.83$ & 0.994 \\
\hline & $7^{\text {th }}$ day on MV & $15.64 \pm 3.97$ & $18.42 \pm 7.51$ & 0.432 \\
\hline & Last day on MV & $17.89 \pm 4.11$ & $28.04 \pm 6.67$ & $0.000 *$ \\
\hline \multirow{3}{*}{$\begin{array}{l}\text { Pressure support } \\
\text { (PS) }\end{array}$} & $1^{\text {st }}$ day on $\mathrm{MV}$ & $17.56 \pm 9.11$ & $13.33 \pm 5.33$ & 0.082 \\
\hline & $7^{\text {th }}$ day on MV & $14.56 \pm 8.47$ & $17.25 \pm 5.62$ & $0.001 *$ \\
\hline & Last day on MV & $11.69 \pm 5.10$ & $18.33 \pm 4.67$ & $0.000 *$ \\
\hline \multirow{3}{*}{$\mathrm{Fio}_{2}$} & $1^{\text {st }}$ day on $\mathrm{MV}$ & $51.81 \pm 11.72$ & $51.21 \pm 10.95$ & 0.901 \\
\hline & $7^{\text {th }}$ day on MV & $41.11 \pm 9.86$ & $48.54 \pm 11.84$ & $0.002 *$ \\
\hline & Last day on MV & $35.56 \pm 3.11$ & $48.12 \pm 10.30$ & $0.000 *$ \\
\hline \multirow{3}{*}{ PEEP } & $1^{\text {st }}$ day on MV & $7.06 \pm 2.18$ & $6.21 \pm 1.72$ & 0.150 \\
\hline & $7^{\text {th }}$ day on MV & $5.97 \pm 2.31$ & $7.71 \pm 2.03$ & $0.003 *$ \\
\hline & Last day on MV & $5.47 \pm 1.83$ & $8.21 \pm 1.38$ & $0.000 *$ \\
\hline
\end{tabular}

PEEP positive end expiratory pressure Fio $_{2}$ fraction of inspired oxygen 
Table (3): Mean distribution of succeed and failed patients regarding to Arterial blood gases.

\begin{tabular}{|c|c|c|c|c|}
\hline & \multirow{2}{*}{ Item } & \multirow{2}{*}{$\begin{array}{c}\text { Success }(n=36) \\
\text { Mean } \pm \text { SD }\end{array}$} & \multirow{2}{*}{$\begin{array}{c}\text { Failed }(\mathrm{n}=\mathbf{2 4}) \\
\text { Mean } \pm \text { SD }\end{array}$} & \multirow{2}{*}{ P-value } \\
\hline & & & & \\
\hline \multirow{3}{*}{ PH } & $1^{\text {st }}$ day on MV & $7.39 \pm 0.10$ & $7.34 \pm 0.14$ & 0.230 \\
\hline & $7^{\text {th }}$ day on MV & $7.45 \pm 0.05$ & $7.41 \pm 0.11$ & 0.322 \\
\hline & Last day on MV & $7.45 \pm 0.05$ & $7.38 \pm 0.11$ & $0.008^{*}$ \\
\hline \multirow{3}{*}{$\mathrm{PaCO}_{2}$} & $1^{\text {st }}$ day on $\mathrm{MV}$ & $37.08 \pm 11.54$ & $41.58 \pm 14.35$ & 0.186 \\
\hline & $7^{\text {th }}$ day on MV & $38.33 \pm 7.88$ & $41.08 \pm 10.26$ & 0.209 \\
\hline & Last day on MV & $37.44 \pm 7.43$ & $40.25 \pm 8.75$ & 0.183 \\
\hline \multirow{3}{*}{$\mathrm{PaO}_{2}$} & $1^{\text {st }}$ day on MV & $123.94 \pm 63.48$ & $135.08 \pm 76.73$ & 0.546 \\
\hline & $7^{\text {th }}$ day on MV & $127.69 \pm 45.17$ & $135.54 \pm 78.79$ & 0.821 \\
\hline & Last day on MV & $122.61 \pm 34.15$ & $121.08 \pm 44.60$ & 0.769 \\
\hline \multirow{3}{*}{$\mathrm{HCO}_{3}$} & $1^{\text {st }}$ day on MV & $22.49 \pm 5.53$ & $22.14 \pm 4.97$ & 0.958 \\
\hline & $7^{\text {th }}$ day on MV & $26.23 \pm 5.94$ & $24.99 \pm 5.80$ & 0.424 \\
\hline & Last day on MV & $25.58 \pm 5.29$ & $25.26 \pm 5.57$ & 0.803 \\
\hline \multirow{3}{*}{$\mathrm{SaO}_{2}$} & $1^{\text {st }}$ day on $\mathrm{MV}$ & $94.31 \pm 7.29$ & $94.36 \pm 11.62$ & 0.559 \\
\hline & $7^{\text {th }}$ day on MV & $96.49 \pm 4.53$ & $95.12 \pm 6.37$ & 0.234 \\
\hline & Last day on MV & $97.35 \pm 2.16$ & $94.29 \pm 5.95$ & $0.001 *$ \\
\hline
\end{tabular}

Ph power hydrogen ion, $\mathbf{P a C O}_{2}$ Partial pressure of carbon dioxide, $\mathbf{P a O}_{2}$ pressure of oxygen $\mathrm{HCO}_{3}$ concentration of bicarbonate $\mathrm{SaO2}$ Oxygen saturation.

Table (4): Percentage distribution of studied patients as regard to Weaning criteria scale for all patient $(\mathrm{n}=60)$.

\begin{tabular}{|c|c|c|c|c|c|c|}
\hline \multirow{2}{*}{\multicolumn{2}{|c|}{ Item }} & \multicolumn{2}{|c|}{ Success $(n=36)$} & \multicolumn{2}{|c|}{ Failed $(n=24)$} & \multirow{2}{*}{ P-value } \\
\hline & & No. & $\%$ & No. & $\%$ & \\
\hline \multirow[t]{5}{*}{ Subjective assessment } & Adequate cough & 8 & 22.2 & 3 & 12.5 & 0.500 \\
\hline & No neuromuscular blocking agent & 35 & 97.2 & 18 & 75.0 & $0.018^{*}$ \\
\hline & Absence of excessive secretion & 7 & 19.4 & 4 & 16.7 & 1.000 \\
\hline & Reversal of the underlying cause & 27 & 75.0 & 5 & 20.8 & $0.000^{*}$ \\
\hline & No adequate sedation & 36 & 100.0 & 21 & 87.5 & 0.059 \\
\hline \multirow[t]{7}{*}{ Objective measures } & Stable cardiovascular status & 30 & 83.3 & 15 & 62.5 & 0.068 \\
\hline & Heart rate $\leq 140$ beat/ minute & 33 & 91.7 & 20 & 83.3 & 0.422 \\
\hline & No active myocardial ischemia & 36 & 100.0 & 21 & 87.5 & 0.059 \\
\hline & Adequate hemoglobin level $\geq 8 \mathrm{~g} / \mathrm{dl}$ & 33 & 91.7 & 17 & 70.8 & 0.073 \\
\hline & Systolic Blood pressure $90-160 \mathrm{mmhg}$ & 36 & 100.0 & 19 & 79.2 & $0.008 *$ \\
\hline & Afebrile $36-38^{\circ} \mathrm{c}$ & 22 & 61.1 & 12 & 50.0 & 0.395 \\
\hline & $\begin{array}{l}\text { No or minimal vasopressor } \leq 5 \mathrm{micro} / \\
\mathrm{kg} / \text { minute }\end{array}$ & 35 & 97.2 & 17 & 70.8 & $0.005^{*}$ \\
\hline \multirow[t]{7}{*}{ Adequate oxygenation } & Tidal volume $\geq 5 \mathrm{ml} / \mathrm{kg}$ & 35 & 97.2 & 17 & 70.8 & $0.005^{*}$ \\
\hline & Respiratory rate $\leq 25 /$ minute & 35 & 97.2 & 21 & 87.5 & 0.292 \\
\hline & Pao2 $\geq 60$ & 36 & 100.0 & 19 & 79.2 & $0.008 *$ \\
\hline & Paco $2 \leq 60$ & 36 & 100.0 & 21 & 87.5 & 0.059 \\
\hline & $\mathrm{PEEP} \leq 8 \mathrm{cmH} 2 \mathrm{o}$ & 33 & 91.7 & 17 & 70.8 & 0.073 \\
\hline & $\mathrm{PH} \geq 7.30$ & 36 & 100.0 & 18 & 75.0 & $0.003 *$ \\
\hline & $\mathrm{Sa} 02 \geq 90 \%$ & 33 & 91.7 & 17 & 70.8 & 0.073 \\
\hline
\end{tabular}

SaO2 Oxygen saturation. 
Table (5): Relationship between duration on mechanical ventilation and incidence of risk factors contributing to delay weaning for all patient $(\mathbf{n}=\mathbf{6 0})$.

\begin{tabular}{|c|c|c|c|}
\hline \multirow{2}{*}{ Item } & & Duration on MV & \multirow{2}{*}{ P-value } \\
\hline & & Mean \pm SD & \\
\hline \multirow{2}{*}{ Infections } & Yes & $16.73 \pm 16.41$ & \multirow{2}{*}{$0.025^{*}$} \\
\hline & No & $10.26 \pm 4.54$ & \\
\hline \multirow{2}{*}{ Respiratory disorder } & Yes & $13.64 \pm 12.31$ & \multirow{2}{*}{0.216} \\
\hline & No & $9.60 \pm 3.25$ & \\
\hline \multirow{2}{*}{ C.V.S disorder } & Yes & $13.19 \pm 13.10$ & \multirow{2}{*}{0.677} \\
\hline & No & $12.00 \pm 7.85$ & \\
\hline \multirow{2}{*}{ Electrolyte disturbance } & Yes & $9.83 \pm 3.87$ & \multirow{2}{*}{0.105} \\
\hline & No & $14.50 \pm 13.46$ & \\
\hline \multirow{2}{*}{ Neuromuscular dysfunction } & Yes & $11.06 \pm 3.99$ & \multirow{2}{*}{0.467} \\
\hline & No & $13.31 \pm 12.75$ & \\
\hline \multirow{2}{*}{ Nutritional disorder } & Yes & $14.05 \pm 13.12$ & \multirow{2}{*}{0.171} \\
\hline & No & $10.00 \pm 3.44$ & \\
\hline \multirow{2}{*}{ Renal impairment } & Yes & $10.52 \pm 7.98$ & \multirow{2}{*}{0.207} \\
\hline & No & $14.14 \pm 12.46$ & \\
\hline \multirow{2}{*}{ Hepatic impairment } & Yes & $14.91 \pm 10.78$ & \multirow{2}{*}{0.448} \\
\hline & No & $12.12 \pm 10.96$ & \\
\hline
\end{tabular}

Table (6): Relationship between length of stay and incidence of risk factors contributing to delay weaning for all patient $(n=60)$.

\begin{tabular}{|c|c|c|c|}
\hline \multirow{2}{*}{ Item } & & Length of ICU stay & \multirow{2}{*}{ P-value } \\
\hline & & Mean \pm SD & \\
\hline \multirow{2}{*}{ Infections } & Yes & $18.59 \pm 18.83$ & \multirow{2}{*}{$0.037 *$} \\
\hline & No & $11.68 \pm 5.15$ & \\
\hline \multirow{2}{*}{ Respiratory disorder } & Yes & $15.13 \pm 14.09$ & \multirow{2}{*}{0.326} \\
\hline & No & $11.47 \pm 3.78$ & \\
\hline \multirow{2}{*}{ C.V.S disorder } & Yes & $14.72 \pm 15.34$ & \multirow{2}{*}{0.741} \\
\hline & No & $13.64 \pm 8.13$ & \\
\hline \multirow{2}{*}{ Electrolyte disturbance } & Yes & $10.96 \pm 4.79$ & \multirow{2}{*}{0.097} \\
\hline & No & $16.39 \pm 15.25$ & \\
\hline \multirow{2}{*}{ Neuromuscular dysfunction } & Yes & $12.11 \pm 4.11$ & \multirow{2}{*}{0.394} \\
\hline & No & $15.12 \pm 14.56$ & \\
\hline \multirow{2}{*}{ Nutritional disorder } & Yes & $15.54 \pm 15.02$ & \multirow{2}{*}{0.265} \\
\hline & No & $11.76 \pm 4.00$ & \\
\hline \multirow{2}{*}{ Renal impairment } & Yes & $12.16 \pm 8.39$ & \multirow{2}{*}{0.282} \\
\hline & No & $15.69 \pm 14.57$ & \\
\hline \multirow{2}{*}{ Hepatic Impairment } & Yes & $15.36 \pm 11.50$ & \multirow{2}{*}{0.738} \\
\hline & No & $13.96 \pm 12.71$ & \\
\hline
\end{tabular}

Table (7): Assessment of predictors of weaning at the $7^{\text {th }}$ day of mechanical ventilation $\&$ APACHE score, RSBI and FOUR score

\begin{tabular}{|c|c|c|c|c|}
\hline \multirow{2}{*}{\multicolumn{2}{|c|}{ Item }} & Success $(n=36)$ & Failed $(n=24)$ & \multirow{2}{*}{ P-value } \\
\hline & & Mean \pm SD & Mean \pm SD & \\
\hline \multicolumn{2}{|c|}{ APACHE score } & $17.69 \pm 4.19$ & $18.29 \pm 5.92$ & 0.694 \\
\hline \multicolumn{2}{|c|}{ RSBI } & $41.47 \pm 8.52$ & $60.40 \pm 16.44$ & $0.000^{*}$ \\
\hline \multirow[t]{3}{*}{ FOUR score } & $1^{\text {st }}$ day on MV & $7.91 \pm 3.55$ & $7.17 \pm 3.48$ & 0.380 \\
\hline & $7^{\text {th }}$ day on MV & $11.39 \pm 2.40$ & $8.57 \pm 3.60$ & $0.002 *$ \\
\hline & Last day on MV & $13.14 \pm 1.03$ & $9.14 \pm 3.85$ & $0.000 *$ \\
\hline
\end{tabular}


Table (8) summary of possible factors considered predictors for weaning failure from mechanical ventilator.

\begin{tabular}{|c|c|c|c|}
\hline \multicolumn{2}{|r|}{ Item } & $\begin{array}{c}\text { Failed weaning } \\
\text { Mean } \pm \text { SD }\end{array}$ & $P$ value \\
\hline \multicolumn{2}{|l|}{ Age } & $49.54 \pm 16.69$ & 0.04 \\
\hline \multirow{3}{*}{$\frac{\text { Sex }}{\text { APAC }}$} & no $\%$ & $15 \& 62.5 \%$ & \multirow[b]{2}{*}{0.121} \\
\hline & Female no \% & $9 \& 37.5 \%$ & \\
\hline & & $18.29 \pm 5.92$ & 0.694 \\
\hline \multicolumn{2}{|c|}{ RSBI } & $60.40 \pm 16.44$ & 0.000 \\
\hline \multicolumn{2}{|c|}{ FOUR } & $8.57 \pm 3.60$ & 0.002 \\
\hline \multicolumn{2}{|c|}{ Pao2 } & $121.08 \pm 44.60$ & 0.769 \\
\hline \multicolumn{2}{|c|}{ Paco2 } & $40.25 \pm 8.75$ & 0.183 \\
\hline \multicolumn{2}{|l|}{$\mathbf{P h}$} & $7.38 \pm .11$ & 0.008 \\
\hline \multicolumn{2}{|c|}{ Albumin } & $1.85 \pm .66$ & 0.001 \\
\hline \multicolumn{2}{|c|}{ Creatinine } & $113.12 \pm 61.74$ & 0.645 \\
\hline \multicolumn{2}{|c|}{ Hemoglobin } & $9.31 \pm 1.5$ & 0.008 \\
\hline \multicolumn{2}{|c|}{ WBCs } & $15.37 \pm 4.20$ & 0.001 \\
\hline \multicolumn{2}{|c|}{ Platelets } & $150.92 \pm 82.39$ & 0.000 \\
\hline \multicolumn{2}{|c|}{ Heart rate } & $115.58 \pm 23.04$ & 0.634 \\
\hline \multicolumn{2}{|c|}{ Respiratory rate } & $28.04 \pm 6.67$ & 0.000 \\
\hline \multicolumn{2}{|c|}{ Length of ICU stay } & $16.22 \pm 15.34$ & 0.005 \\
\hline \multicolumn{2}{|c|}{ Duration on MV } & $13.61 \pm 13.54$ & 0.792 \\
\hline
\end{tabular}

Table (1): This table represents the Sociodemographic and clinical data of patients on mechanical ventilator, it was noticed that there was a significant difference between the both groups as regard to age $\mathrm{p}=(.040)$. As regard to weight, height and body mass index it was found that there was no significant difference among both groups. Concerning the primary diagnosis for initiation of mechanical ventilation, there was significance difference with cardiovascular and neurological cause among the both groups success and failed weaning.

Table (2): this table clarifies that ventilator parameters values show a significant statistical difference $(p=0.005,0.000,0.000,0.000$ and 0.000$)$ found between both groups in relation to (Vt, F, PS, $\mathrm{FIO}_{2}$ and PEEP) respectively at the last day on mechanical ventilator. As for, the $7^{\text {th }}$ day on ventilator there was a high significant difference among both group in relation to (PS, $\mathrm{FIO}_{2}$ and PEEP) with ( $p=0.001,0.002$ and 0.003$)$ respectively. Concerning the $1^{\text {st }}$ day on ventilator there was no significant difference among both groups regarding all ventilator parameters.

Table (3): This table revealed that there was no statistical difference between both groups in relation to paco $_{2}, \mathrm{pao}_{2}$ and $\mathrm{Hco}_{3}$ in all days $\left(1^{\mathrm{st}}, 7^{\text {th }}\right.$ and last day on MV). But it noticed that there were a highly significant difference regard $\mathrm{PH}$ and $\mathrm{SaO}_{2}$ at the last day on MV with ( $\mathrm{p}=0.008 \& 0.001)$ respectively.

Table (4): This table reflects the percentage distribution of the weaning criteria sale studied groups at the $7^{\text {th }}$ day on MV. The table shows that there was a significant difference in relation to subjective assessment in No neuromuscular blocking agent and Reversal of the underlying cause with $(\mathrm{p}=0.018 \& 0.000)$ respectively. Concerning to objective measures, there were a significant difference regarding to systolic Blood pressure 90$160 \mathrm{mmhg}$ and no or minimal vasopressor $\leq 5 \mathrm{micro} /$ $\mathrm{kg} /$ minute with $(\mathrm{p}=0.008 \quad \& 0.005)$ respectively. According to adequate oxygenation there were significant differences between both groups related to tidal volume $\geq 5 \mathrm{ml} / \mathrm{kg}, \mathrm{Pao} 2 \geq 60$ and $\mathrm{PH} \geq 7.30$ with $(\mathrm{p}=0.005,0.008$ and 0.003$)$ respectively.

Table (5): Denotes relationship between duration on mechanical ventilation and incidence of risk factors contributing to delay weaning for all patients, it was found that there was a significant difference between patients regarding to the incidence of infections with $(\mathrm{p}=0.025)$.

Table (6): Denotes relationship between length of stay and incidence of risk factors contributing to delay weaning for all patients, it was found that there was a significant difference between patients regarding to the incidence of infections with $(\mathrm{p}=0.037)$.

Table (7): This table demonstrates no significant difference between both groups regarding to the APACHE score system $(\mathrm{p}=0.694)$ on admission. As regard FOUR score and RSBI score it was noticed that there was a statistically significant difference with $(\mathrm{p}=0.000)$.

Table (8): This table summarized some of risk factors contributing to long term mechanical 
ventilation and there was significant difference between both groups in relation to considered risk factors.

\section{Discussion}

Based on the results of the present study; the mean age in group I was smaller than the mean age in group II with statistically significant difference between both groups with. this result is in line with (Yasuyuki, 2018) and (Hong, et al., 2017) who found that there was significant difference with regarding to age

(Alaa, et al., 2013) (Hoda, et al., 2016) disagree with the results of this study and said that there was no significant difference between success and failed groups regarding to age in success and failed groups. Both groups were matched according to sex and body mass index showing no statistically significant difference. These findings were supported by (Adel, et al., 2017) \& (Boniatti, et al., 2015) who found that there was no significant difference between both groups as regard to sex and body mass index.

As regard primary diagnosis during ICU admission, the current study clarifies that the majority of patient were primarily diagnosed as cardiovascular and neurological disorder. This result is confirmed with (Cécile, et al., 2017) who found that there was a significant difference according to cardiovascular and neurological causes. But, (Boniatti, et al., 2015) disagree with the current result as they found the significant difference matched with surgical causes and (Hong, et al., 2017) found that the significant difference related to the respiratory and cardiovascular causes.

The present study illustrated the ventilator parameters showing significant difference related to pressure support and fraction of inspired oxygen. This result is confirmed by (Ya-chun, et al., 2018) who found a significant difference regarding to fraction of inspired oxygen and it disagreed with (Yvon, et al., 2012) who report no significant difference related to pressure support and fraction of inspired oxygen.

As regard tidal volume, the current study showed that the succeed group had a higher tidal volume than the failed group and this result agree with (Sarah, et al., 2014) who reported higher tidal volume in succeed group. But, this result mismatched with (Ali, et al., 2015) \& (Ahmed, et al., 2018) who reported that there was no significant difference related to tidal volume for the succeed group.

In relation to PEEP, the present study reported that the failed group patients showed a higher PEEP than the succeed group and this result disagree with (Yvon, et al., 2012) who showed that is no significant difference related to PEEP among both groups.
The present study added that regarding to arterial blood gases there was a significant difference between both groups related to $\mathrm{pH}$. and no statistical difference concerning to partial pressure of oxygen, carbon dioxide and bicarbonate. And this result supported with (Hala \& Wegdan, 2016) who revealed a significant difference related to $\mathrm{PH}$ without difference according to pao2 and paco2. But, (Viviane, et al., 2014) \& (Sarah, et al., 2014). mentioned the significant difference related to partial pressure of carbon dioxide and this is conflicted with the results of the of the current study.

Regarding to oxygen saturation, this current study demonstrates that the failed group had a lower oxygen saturation than the succeed group and this result is in the same line with (Mohamed, et al., 2014) who found that the failed group had a lower oxygen saturation than succeed group. but (Daniela, et al., 2016) mentioned that there was no significant difference between both groups as regard to oxygen saturation

The current study applied the weaning criteria scale at the $7^{\text {th }}$ day on mechanical ventilator and demonstrated that there was a significant difference related to subjective assessment regarding to reversal of under lying cause and no neuromuscular blocking agents. According to objective measures, the significant difference was found related to systolic blood pressure $90-160 \mathrm{mmhg}$ and no or minimal vasopressor $\leq 5$ micro $/ \mathrm{kg} /$ minute. As for, adequate oxygenation, the significant difference was found in relation to tidal volume $\geq 5 \mathrm{ml} / \mathrm{kg}$, pao $2 \geq 60 \%$ and $\mathrm{PH} \geq 7.30$.

Difficult weaning from mechanical ventilator proved to be multifactorial. In the present study, risk factors that found to be responsible for failure of weaning trials were respiratory disorder which detected in 45 patients $(75 \%)$ of total patients in both groups $(n=60)$, nutritional disorders noticed in 39 patients $(65 \%)$, cardiovascular disorder detected in 27 patients $(45 \%)$, hepato-renal impairment detected in 36 patients (60\%), electrolytes and trace elements disturbance 24 patients (40\%), infection (pulmonary and extrapulmonary) detected in 22 patients $(36.66 \%)$, and neuromuscular disorders presented 18 patients $(30 \%)$. These results matches with the result of (Yehia, et al., 2013) who mentioned that risk factors that found to be responsible for failure of weaning trials were as regard to previous study $(69.1 \%, 87 \%$, $58 \%, 48 \%, 83.8,100 \%$ and $45 \%$ ) respectively.

In relation to duration of MV \& length of ICU stay and occurrence of factors leading to difficult weaning, the current study revealed that increasing the duration on mechanical ventilation and length of ICU stay leading to increase the incidence of infections (pulmonary and extrapulmonary) this 
result was in the same line with (Boniatti, et al., 2015) who mentioned that there was significant difference related to infection. regarding to respiratory, cardiovascular, electrolytes, neuromuscular, nutritional, renal and hepatic factors (complications) the present study show no significant difference between both groups. But, (Vivek, et al., 2017) disagreed with the present study as they found a significant difference related to respiratory, neuromuscular, cardiovascular, renal, and electrolytes complications.

The present study demonstrated that the success group had a shorter length of ICU stay and this result is on line with (Mohamed, et al., 2014) and (Yasuyuki, 2018) who found that the length of ICU stay had a significant difference between the both groups. But they disagree with the results of current study concerning the duration on mechanical ventilation as the current study show no statistically significant difference related to duration of mechanical ventilation.

Concerning the results of current study, there was no significant difference related to APACHE score between both groups and this result is supported by (Ya-chun, et al., 2018) who found that there was no significant difference related to the APACHE score with. but (Vasilios, et al., 2011) disagree with the results who found significant difference related to it. In relation to weaning predictors, this study found that there was significant difference among both groups related to recurrent spontaneous breathing trials and FOUR score and this is confirmed with (Said, et al., 2016), (Hala \& Wegdan, 2016) \& (Yehia, et al., 2013) who found significant difference among the both groups. (Ahmed, et al., 2018) \& (Alaa, et al., 2013) disagree with the current study as they found no significant difference regarding to RSBI among both groups.

\section{Conclusion}

a highly statistically significant relation was found regarding to factors as age, length of ICU stays, RSBI, PH, hemoglobin, WBCs, platelets count and respiratory rate.

\section{Recommendations}

1-good monitoring of the cardiovascular assessment with cardiologists

2- the weaning indexes have some limitations, related to study population

3- integration with other departments should be morely supported.

\section{References}

1. Adel H., Howida M., Doaa M., \& Ahmed M., (2017): assessment of weaning failure in chronic obstructive pulmonary disease patients under mechanical ventilation in Zagazig university hospitals, Egyptian journal of chest disease and tuberculosis, 66:65-74.

2. Ahmed A., Sameh E., Walaa S., \& Mohamed L., (2018): role of diaphragmatic rapid shallow breathing index in predicting weaning outcome in patients with acute exacerbation of COPD, International journal of COPD, 13:1565-1662.

3. Alaa E., Mohamed W., Adel S., \& Abdel Raheem Y., (2013): evaluation of the minute ventilation recovery time as a predictor of weaning in mechanically ventilated COPD patients in respiratory failure, Egyptian Journal of Chest Diseases and Tuberculosis, 62:287-292.

4. Ali A., Osama F., Aml A., Mahmoud M., \& Ahmed A., (2015): Evaluation of some predictors for successful weaning from mechanical ventilation, Egyptian Journal of Chest Diseases and Tuberculosis, 64(3):703-707.

5. Andres L., \& Jorge, I., (2018): Ventilator Management, National Center for Biotechnology Information, U.S. National Library of Medicine, StatPearls.

6. Béduneau G., Pham T., Schortgen F., Piquilloud L., Zogheib E., Jonas M., (2017): Epidemiology of weaning outcome according to a new definition, The WIND study, American Journal of Respiratory Critical Care Medicine, 195(6):772-783.

7. Boniatti M., Marcio P., Daniele M., patricia C., (2015): the reality of patients requiring prolonged mechanical ventilation: a multicenter study, Rev Bras Ter intensiva, 27(1):26-35.

8. Daniela G., Juliana A., \& Daniel O., (2016): Variations in the measurement of weaning parameters of mechanical ventilation in Fortaleza hospitals, Revista Brasileira de Terapia Intensiva, 22(2).

9. Elizabeth M., Carlos S., Rogéria T., Diva T., Joelna E., (2014): Nursing care of hospitalized patients receiving, mechanical ventilation in intensive care units, Revista de Enfermagem Referência, pp55-62.

10. Elkins M., \& Dentice R., (2015): Inspiratory muscle training facilities weaning from mechanical ventilation among patients in the intensive care unit: a systematic review, journal of physiotherapy, 6(3)125-134.

11. Guillermo B., Mohamud E., \& Jan B., (2016): Prolonged mechanical ventilation and chronic critical illness, Journal of Thoracic Disease, 8(5): 751-753. 
12. Mohammad H., \& Ali W., (2016): predictive value of end tidal co2, lung mechanics and other standard parameters for weaning neurological patients from mechanical ventilation, Egyptian Journal of Chest Diseases and Tuberculosis, 65:105-112.

13. Herwanto V., Wang Y., Shojaei M., Tang B., McLean A., (2018): 38th International Symposium on Intensive Care and Emergency Medicine, BioMed Central, critical care journal, 22:82.

14. Abu Youssef H., Alaa E., Ahmed M., Shaban M., \& Hamed, (2016): predictive value of rapid shallow breathing index in relation to the weaning outcome in ICU patients, Egyptian Journal of Chest Diseases and Tuberculosis, 65:465-472.

15. Hong J., Jin S., Seong A., Tae O., Cheol K., (2017): clinical factors associated with weaning failure in patients requiring prolonged mechanical ventilation, journal of thoracic disease, 9(1):143150.

16. Hossam Z., Alireza B., Ahmed N., \& Saeed S., (2016): Ventilator Weaning and Spontaneous Breathing Trials; an Educational Review, Creative Commons Attribution Noncommercial license, US National Library of Medicine, 4(2): 65-71.

17. Hough C., Caldwell E., Cox C., (2015): Development and validation of a mortality prediction model for patients receiving 14 days of mechanical ventilation, critical care medicine journal, 43:2339-45.

18. Karir V., Hough C., Daniel S., (2012): sedation practices in a cohort of critically ill patients receiving prolonged mechanical ventilation, Minerva anesthesiology, 78:801-809.

19. Knaus W., Draper E., \& Wagner D., (1985): APACHE II: a severity of disease classification system. Critical Care Medicine ,13(10):818-829.

20. Lone N., \& Walsh T., (2011): prolonged mechanical ventilation in critically ill patients: epidemiology, outcomes and modelling the potential cost consequences of establishing a regional weaning unit, journal of critical care, 15: R102.

21. Loss S., Oliveira R., Maccari J., (2015): the reality of patients requiring prolonged mechanical ventilation: a multicenter study, rev Bras ter intensiva, 27:26-35.

22. Mariana H., Marine V., Beatrix C., Johannes M., Zafeiris L., (2018): Can inspiratory muscle training improve weaning outcomes in difficult to wean patients? A protocol for a randomized controlled trial (IMweanT study), BMJ open,8: e021091.
23. Michael E., \& Lucila O., (2014): Generation of Knowledge for Clinical Decision Support: Statistical and Machine Learning Techniques, 2nd ed, Clinical Decision Support, Elsevier, 309-337.

24. Mifsud B., Sanctuary T., Warren A., (2016): prospective observational cohort study of patients with weaning failure admitted to a specialist weaning, rehabilitation and home mechanical ventilation center, BMJ open, 6: e010025.

25. Mohamed S., Hesham A., \& Ahmed M., (2014): effect of respiratory muscles training in weaning of mechanically ventilated COPD patients, Egyptian Journal of Chest Diseases and Tuberculosis, 63:679-687.

26. Mohammad R., Abbas A., Azadeh M., Farrokh T., Leyla K., \& Maryam A., (2017): Evaluation of the relationship between score results of APACHE-IV scoring system and mortality rate of patients admitted to the Intensive Care Unit (ICU) of the burn section, Biomedical Research, 28(6).

27. patricia M., \& Dorrie K., (2018): critical care nursing, A Holistic Approach, $11^{\text {th }}$ ed, Wolters Kluwer Health | Lippincott Williams\& Wilkins.

28. Quellette D., Patel .S, Girard T., \& Morris P., (2017): liberation from mechanical ventilation in critically ill adults: an official American college of chest physicians, American thoracic society clinical practice guidelines trials, protocols minimizing sedation and noninvasive ventilation, chest, 151(1):166-180.

29. Rojek A., Hombach R., Gierek D., (2015): a single center seven-year experience with mechanical ventilation weaning Anaesthesiology intensive Ther journal, 47:204-209.

30. Rose L., \& Fraser I., (2012): patient characteristics and outcomes of a provincial prolonged- ventilation weaning centre: a retrospective cohort study, can respiratory journal, 19:216-220.

31.Said T., Chaari A., Hakim K., Hamama D., \& Casey W., (2016): Usefulness of full outline of unresponsiveness score to predict extubation failure in intubated critically-ill patients: a pilot study, International Journal of Critical Illness and Injury Science, 6(4):172-7.

32.Sarah S., Jin H., Jeong M., \& Sungwon N., (2014): Predicting Delayed Ventilator Weaning after Lung Transplantation: The Role of Body Mass Index, The Korean journal of Critical Care Medicine, 29(4):273-280.

33. Vasilios P., Ioanna C., Maglaveras N., \& Ioannis P., (2011): Study of multiparameter respiratory pattern complexity in surgical critically ill patients during weaning trials, journal of BMC Physiology, 11(1):2. 
34. Vivek K., Carmen G., Walter T., \& Hannah W., (2017): Relationship Between ICU Length of Stay and Long-term Mortality for Elderly ICU Survivors, Critical Care Medicine journal ,44(4): 655-662.

35. Viviane M., Márcio M., Cristiano F., \& Elaine A., (2014): The Modified Integrative Weaning Index as a Predictor of Extubation Failure, journal of RESPIRATORY CARE, 59(7).

36. Wijdicks E., Bamlet W., Maramattom B., Manno E., McClelland R., (2005): Validation of a new coma scale: The FOUR score, annals of neurology, 58(4):585-593.

37. Ya- chun C., Kuo-tung H., Yu-mu C., Chinchou W., Yi-his W., (2018): ventilator dependence risk score for the prediction $\mathrm{f}$ prolonged mechanical ventilation who survive sepsis /septic shock with respiratory, scientific reports, 8:5650.

38. Yasuyuki Okabe, (2018): Risk factors for prolonged mechanical ventilation in patients with severe multiple injuries and blunt chest trauma: a single center retrospective case-control study, acute medicine and surgery journal, 5:166-172.

39. Yehia K., Emad I., Ahmed S., Mohamed I., \& Amany E., (2013): assessment of risk factors responsible for difficult weaning from mechanical ventilation in adults, Egyptian Journal of Chest Diseases and Tuberculosis, 61:159-166.

40. Yvon R., Wissem C., Stéphane L., \& Francis L., (2012): Predictive value of the physiological dead space/tidal volume ratio in the weaning process of mechanical ventilation in children, Journal de Pediatric, 88(3). 